\title{
Meta-analysis of the Risk Factors of Thrombosis in the Perioperative Period of the Orthopedics Spinal Surgery
}

\author{
HAO. CHENG, XING.ZHONG. LI, JUN. XUAN AND YANG WU* \\ Department of Spine Surgery, Jinhua Municipal Central Hospital, No. 365 Renmin East Road, Jinhua, Zhejiang 321000 , \\ China
}

\author{
Cheng et al.: Meta-analysis of the Risk Factors of Thrombosis
}

\begin{abstract}
To explore the specific risk factors of thrombosis in the perioperative period of orthopedics spinal surgery, a search was conducted with specific keywords in PubMed, EMbase, the Cochrane Library, China National Knowledge Infrastructure, WanFang Data, very important paper and Web of Science databases between January 2015 and December 2019. Two researchers independently screened the literature, extracted the data and cross-checked. RevMan 5.3 software was used for meta-analysis. A total of 6 articles were included in this study, with a total of 23106 patients. The results of meta-analysis showed that the age standard mean difference $(=0.39,95 \%$ confidence intervals $0.18,0.59, p=0.0002)$, blood loss $($ mean difference $=35.26,95 \%$ confidence intervals $30.18,40.34, p=0.00001$ ), and operation time (mean difference $=13.49$, $95 \%$ confidence intervals $5.34,21.64, p=0.001$ ) of the experimental group were significantly higher than

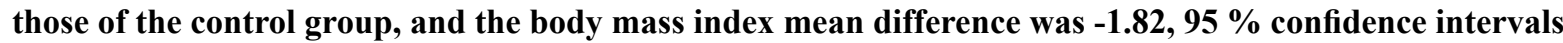
$(-2.79,-0.85, p=0.0002)$ of the experimental group was significantly lower than that of the control group. There was no significant difference in the number of female (odds ration $=2.23,95 \%$ confidence intervals $0.65,7.69, p=0.2$ ) and male (odds ration $=0.65,95 \%$ confidence intervals $\mathrm{CI} 0.32,1.32, \mathrm{p}=0.23$ ) patients between the experimental group and the control group. Age, operation time, blood loss, and body mass index were the risk factors of thrombosis in the perioperative period of orthopedics spinal surgery.
\end{abstract}

Key words: Spinal operation, perioperative period, thrombosis, risk factors, meta

Many complications often occur during the perioperative period of orthopedic spinal surgery, among which the pulmonary embolism and deep venous thrombosis were one of the common complications ${ }^{[1-5]}$. Previous studies have shown that patients with fracture of hip and knee osteoarthritis were more likely to form such thrombi during the perioperative period, with an incidence of up to $84 \%$ [6]. Therefore, clinic should prevent thrombosis actively. However, there were many risk factors of thrombosis in the perioperative period of orthopedic spinal surgery, so it is difficult to grasp the preventive measures. Therefore, it is necessary to study the risk factors of thrombosis. A large number of studies have analyzed the risk factors of thrombosis in the perioperative period of orthopedic spinal surgery ${ }^{[7-12]}$, but different conclusions were often drawn due to small sample size, deviations in subject selection and other factors. Therefore, this study comprehensively searched the literature on thrombosis in the perioperative period of orthopedic spinal surgery and analyzed the risk factors of venous thrombosis reported through metaanalysis, to make these conclusions more reliable. Studies reporting venous thrombosis in the perioperative period of orthopedic spinal surgery published at home and abroad were selected without any restriction to the languages. The studies published from January 2015 to December 2019 on the subject patients with venous thrombosis were selected, which included full-text literature and when not available, conference reports, reviews were included. Keywords in English used included spinal surgery, deep venous thrombosis, venous thromboembolism, and risk factors were searched in the PubMed, EMbase, The Cochrane Library, China National Knowledge Infrastructure (CNKI), WanFang Data, very important paper (VIP) and Web of Science databases. There were no restrictions on languages. The searched time was from January 2015 to December 2019. Two researchers independently screened the literature, extracted the data, and cross-checked. If there were differences, these were resolved through discussion or consultation with a third party. When screening the literature, obviously irrelevant literature was eliminated through screening the titles, and then the abstracts and full text were scrutinized to determine whether to include or not. When necessary, the original research author was 
contacted to obtain additional information that would be of importance to this study. The risk factors of venous thrombosis in the perioperative period of orthopedic spinal surgery were meta-analysed. Continuous variables such as, age, operation time, blood loss, body mass index (BMI) were analyzed by the mean difference (MD) and $95 \%$ confidence intervals (CI) and the binary variables (gender) were analyzed by odds ratio (OR) and $95 \% \mathrm{CI}$. The heterogeneity among the results was analyzed by the $\chi^{2}$ test, and the heterogeneity was quantitatively judged by $\mathrm{I}^{2}$. If there was no statistical heterogeneity among the results of each study, the fixed effect model was used for metaanalysis. If there was statistical heterogeneity among the results, the source of the heterogeneity was further analyzed. After excluding the obvious clinical heterogeneity, the random effect model is used for meta-analysis. In this paper, a total of 5345 related reports were preliminarily detected by software, and finally 6 reports on 23106 patients were included in this study ${ }^{[14-19]}$ grouped into 596 patients in the experimental group and 22510 patients in the control group. The literature screening process and results were shown in (fig. 1). The basic characteristics of the inclusion study were shown in Table 1. A total of 6 reports ${ }^{[14-19]}$ were included, which reported data of 23106 patients. The results of the random effect model meta-analysis showed that the age of the study group was significantly higher than that of the control group standard mean difference $(\mathrm{SMD})=0.39,95 \%$ CI 0.18 ,
$0.59, \mathrm{p}=0.0002$, (fig. 2). A total of 5 reports $^{[14,15,17-19]}$ were included, comprising of 22972 patients. The results of the random effect model meta-analysis showed that there was no significant difference in the number of female patients between the experimental group and the control group (OR=2.23, $95 \%$ CI 0.65 , 7.69, $\mathrm{p}=0.2$, fig. 3). In 5 reports $^{[14,15,17-19]}$ that were analyzed on 23062 patients, the results of which showed that there was no significant difference in the number of male patients between the experimental group and the control group (OR=0.65, $95 \%$ CI 0.32 , 1.32, $\mathrm{p}=0.23$, fig. 4). A total of 5 reports ${ }^{[14-18]}$, which reported 1829 patients, the meta-analysis of the fixed effect model showed that the operation time of the experimental group was significantly longer than that of the control group ( $\mathrm{MD}=13.49,95 \%$ CI 5.34, 21.64, $\mathrm{p}=0.001$, fig. 5). In 4 studies $^{[14,15,17-18]}$ on 785 patients, the meta analysis of the fixed effect model showed that the blood loss in the experimental group was significantly higher than that in the control group $(\mathrm{MD}=35.26,95 \%$ CI 30.18, 40.34, $\mathrm{p}=0.00001$, fig. 6). In 4 studies $^{[14,15,17,18]}$ that included 785 patientsm meta analysis of the fixed effect model showed that the BMI of the experimental group was significantly lower than that of the control group ( $\mathrm{MD}=-1.82,95 \% \mathrm{CI}-2.79$, $-0.85, p=0.0002$, fig. 7). In recent years, due to the influence of many factors, more and more patients are undergoing orthopedic spinal surgery with a concomitant increase in the incidence especially of thrombus in the perioperative period of orthopedic

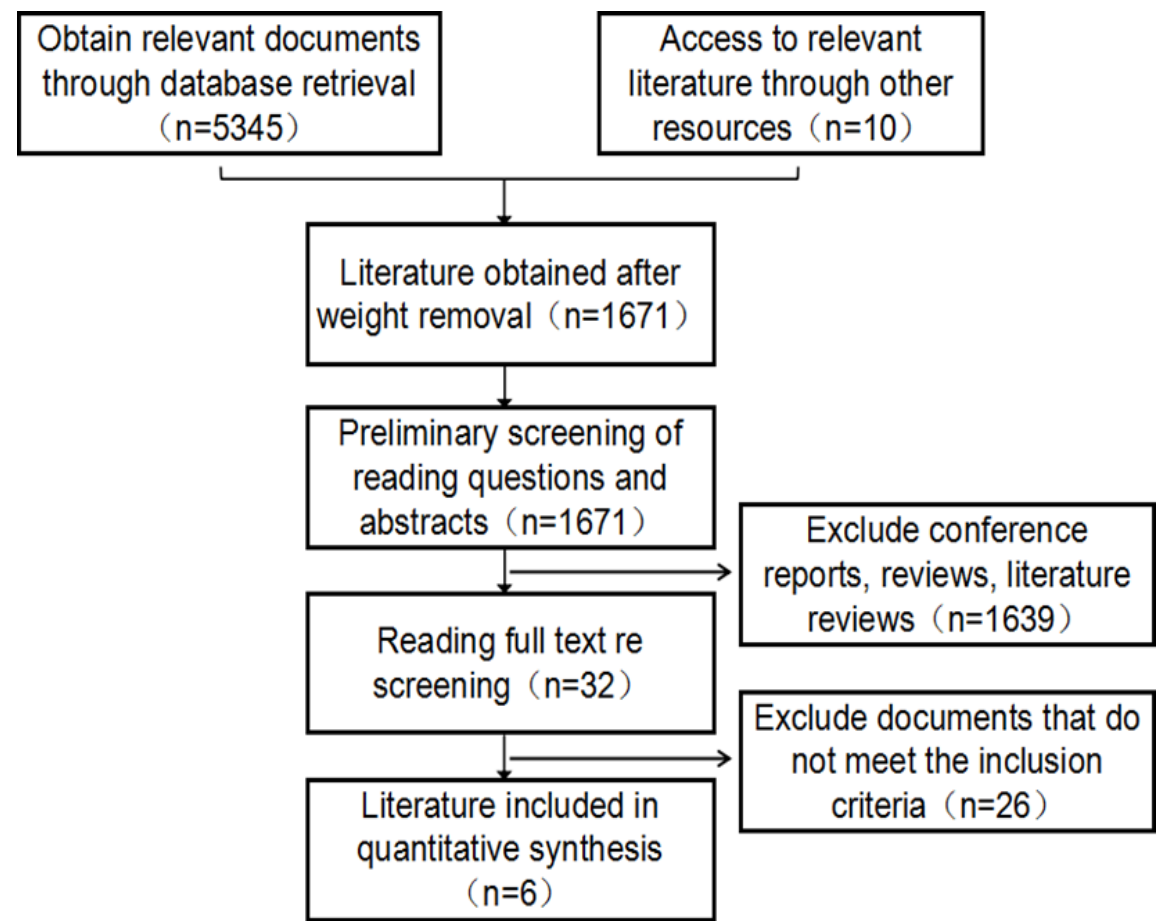

Fig. 1: The literature screening process and results 
www.ijpsonline.com

TABLE 1: THE BASIC CHARACTERISTICS OF THE INCLUSION STUDY

\begin{tabular}{|c|c|c|c|c|c|c|c|}
\hline \multirow{2}{*}{$\begin{array}{l}\text { Control } \\
\text { group }\end{array}$} & \multicolumn{2}{|c|}{ Age } & \multicolumn{2}{|c|}{$\begin{array}{c}\text { Gender } \\
\text { (female/male) }\end{array}$} & \multicolumn{2}{|c|}{$\begin{array}{c}\text { Operation time } \\
(\min )\end{array}$} & \multirow{2}{*}{$\begin{array}{c}\text { Blood loss (g) } \\
\begin{array}{c}\text { Experimental } \\
\text { group }\end{array}\end{array}$} \\
\hline & $\begin{array}{l}\text { Experimental } \\
\text { group }\end{array}$ & Control group & $\begin{array}{l}\text { Experimental } \\
\text { group }\end{array}$ & Control group & $\begin{array}{l}\text { Experimental } \\
\text { group }\end{array}$ & $\begin{array}{l}\text { Control } \\
\text { group }\end{array}$ & \\
\hline 421 & $68.8 \pm 13.2$ & $60.7 \pm 14.9$ & $27 / 11$ & $180 / 241$ & $239.2 \pm 123.6$ & $226.9 \pm 117.6$ & $517.0 \pm 651.1$ \\
\hline 60 & $75 \pm 12.5$ & $70.5 \pm 10.8$ & $11 / 9$ & $22 / 38$ & $212.5 \pm 37.7$ & $177.5 \pm 40.0$ & $110.0 \pm 23.3$ \\
\hline 1024 & $63.5 \pm 13.1$ & $53.04 \pm 14.3$ & & & $123.3 \pm 34.8$ & $94.05 \pm 34.4$ & \\
\hline 114 & $75.5 \pm 11.3$ & $66.6 \pm 14.0$ & $13 / 2$ & $80 / 34$ & $145.9 \pm 42.2$ & $134.7 \pm 36.5$ & $175 \pm 33.5$ \\
\hline 74 & $44.9 \pm 9.2$ & $43.6 \pm 13.2$ & $9 / 34$ & $34 / 40$ & $231.7 \pm 39.6$ & $239.5 \pm 27.6$ & $125.2 \pm 17.8$ \\
\hline 20817 & $64.78 \pm 14.04$ & $61.5 \pm 15.97$ & $219 / 141$ & $11917 / 8900$ & & & \\
\hline
\end{tabular}

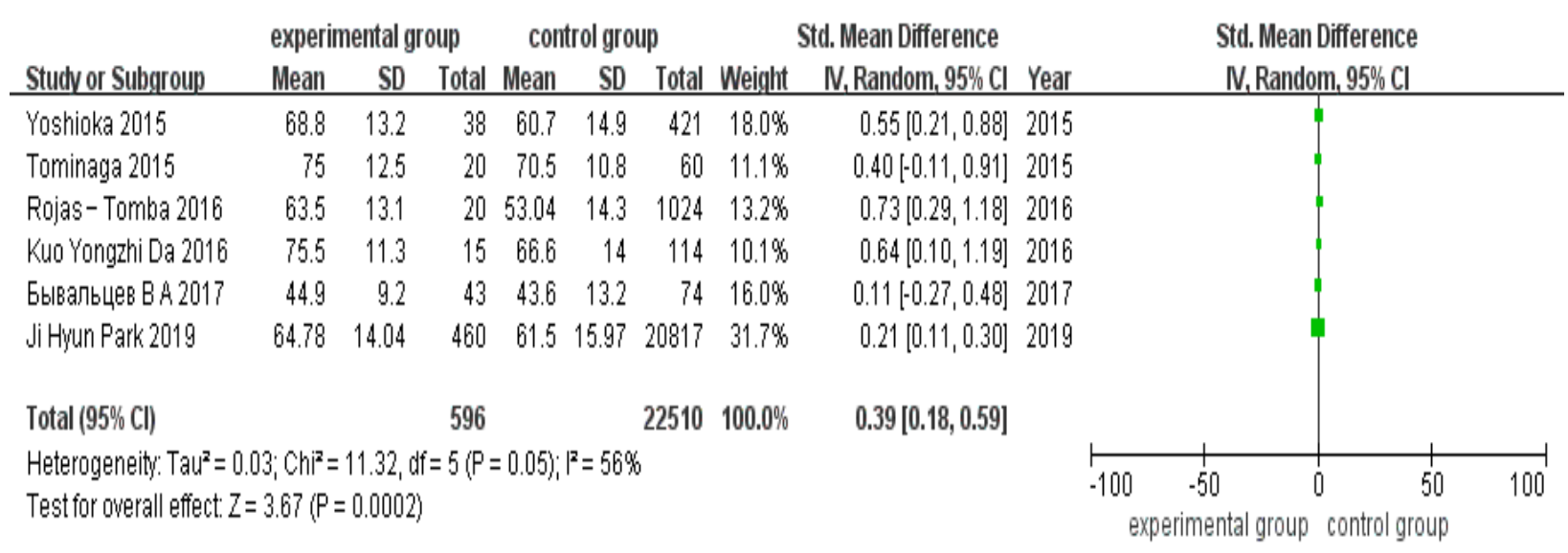

Fig. 2: Meta-analysis of the age comparison of venous thrombosis patients Meta-analysis of the age comparison of venous thrombosis patients in the perioperative period of orthopedic spinal surgery between the experimental group and the control group

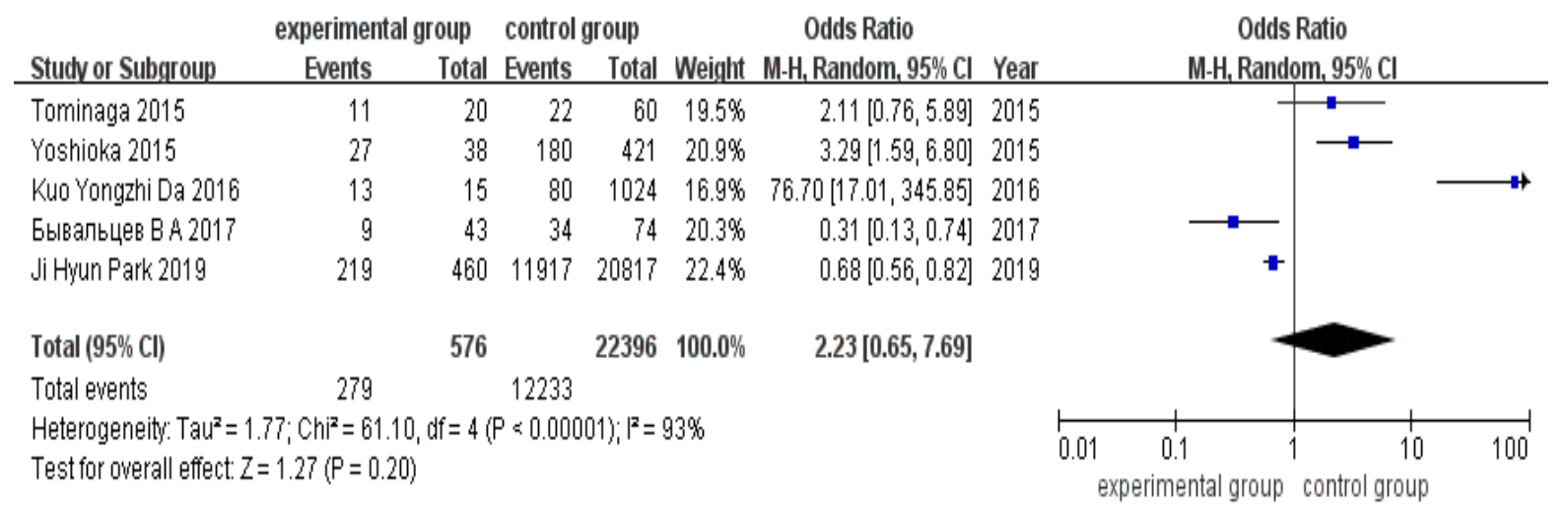

Fig. 3: Meta-analysis of female patients comparison of venous thrombosis patients

Meta-analysis of female patients comparison of venous thrombosis patients in the perioperative period of orthopedic spinal surgery between the experimental group and the control group

spinal surgery. Due to the high incidence of thrombosis in the perioperative period, the prognosis of patients undergoing orthopedic spinal surgery was affected along with the quality of life of patients. Therefore, many studies focused on the risk factors of thrombosis in the perioperative period of orthopedic spinal surgery, to further prevent the formation of thrombus in the clinic through the analysis of the influencing factors of thrombosis. The results of this study found that the age, operation time, blood loss, and BMI were related to thrombosis in the perioperative period of orthopedic spinal surgery. Age, blood loss, and BMI were the high risk factors for thrombosis in the perioperative period of orthopedic spinal surgery. The results of meta- 
analysis showed that the age of the experimental group was significantly higher than that of the control group. The blood loss in the experimental group was significantly higher than that of the control group. The BMI of the experimental group was significantly lower than that of the control group. This showed that the age of the patients, blood loss, and BMI were positively correlated with the rate of thrombosis, which is consistent with the previously reported conclusions ${ }^{[20]}$.
However, Yoshioka et al. ${ }^{[14]}$, Rojas-Tomba et al. ${ }^{[15]}$ and other workers pointed out that the gender should be considered in the perioperative risk factors of orthopedic spinal surgery. However, according to the meta-analysis of the gender related factors, there was no significant difference in the number of female and male patients between the experimental group and the control group. Gender factors have little effect on the thrombosis in perioperative period of orthopedic spinal surgery, which

\begin{tabular}{|c|c|c|c|c|c|c|c|c|c|c|c|}
\hline \multirow[b]{2}{*}{ Study or Subgroup } & \multicolumn{2}{|c|}{ experimental group } & \multicolumn{2}{|c|}{ control group } & \multicolumn{3}{|c|}{ Odds Ratio } & \multicolumn{4}{|c|}{ Odds Ratio } \\
\hline & Events & Total & Events & Total & Weight & M-H, Random, $95 \% \mathrm{Cl}$ & Year & & M-H, Rando & m. $95 \% \mathrm{Cl}$ & \\
\hline Tominaga 2015 & 9 & 20 & 38 & 60 & $17.9 \%$ & $0.47[0.17,1.32]$ & 2015 & & $\longrightarrow$ & & \\
\hline Yoshioka 2015 & 11 & 38 & 241 & 421 & $22.0 \%$ & $0.30[0.15,0.63]$ & 2015 & & $\longrightarrow$ & & \\
\hline Kuo Yongzhi Da 2016 & 2 & 15 & 34 & 114 & $12.1 \%$ & $0.36[0.08,1.69]$ & 2016 & & & & \\
\hline Бывальцев В А 2017 & 34 & 43 & 40 & 74 & $20.0 \%$ & $3.21[1.35,7.63]$ & 2017 & & & 一 & \\
\hline Ji Hyun Park 2019 & 141 & 460 & 8900 & 20817 & $28.0 \%$ & $0.59[0.48,0.72]$ & 2019 & & $=$ & & \\
\hline Total (95\% Cl) & & 576 & & 21486 & $100.0 \%$ & $0.65[0.32,1.32]$ & & & & & \\
\hline Total events & 197 & & 9253 & & & & & & & & \\
\hline $\begin{array}{l}\text { Heterogeneity: } \text { Tau }^{2}= \\
\text { Test for overall effect: }\end{array}$ & $\begin{array}{l}15 ; \mathrm{Chi}^{2}=18 \\
1.20(\mathrm{P}=0 .\end{array}$ & $=4$ (F & $P=0.001$ & $; 1^{2}=789$ & & & & 0.0 & 0.1 & 10 & 100 \\
\hline
\end{tabular}

Fig. 4: Meta-analysis of male patients comparison of venous thrombosis patients

Meta-analysis of male patients comparison of venous thrombosis patients in the perioperative period of orthopedic spinal surgery between the experimental group and the control group

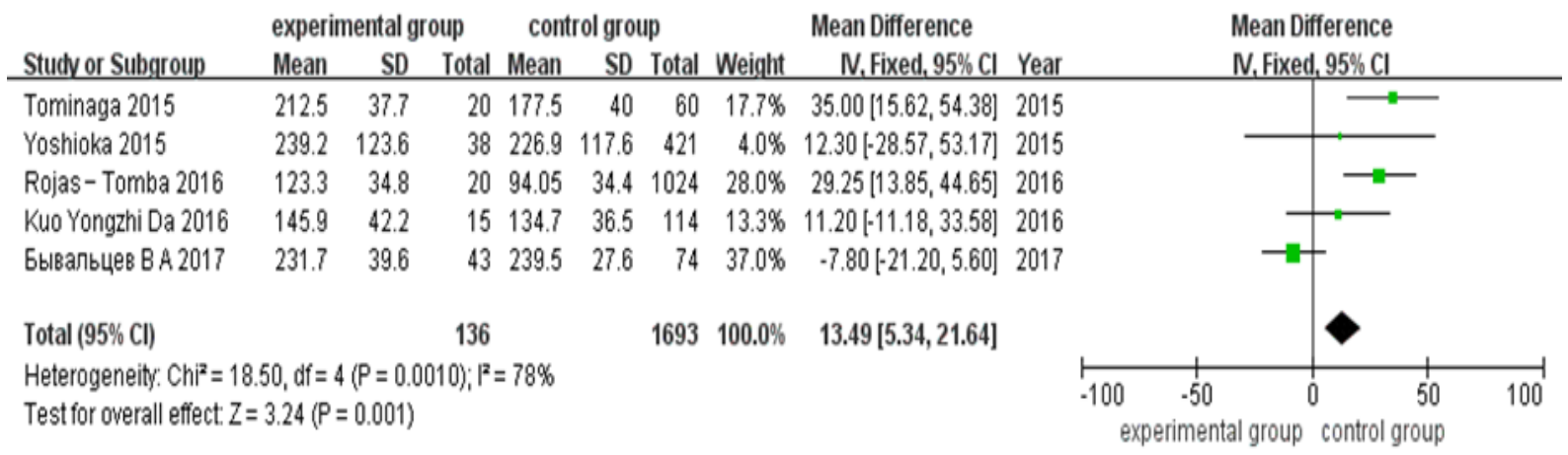

Fig. 5: Meta-analysis of the operation time comparison of venous thrombosis patients

Meta-analysis of the operation time comparison of venous thrombosis patients in the perioperative period of orthopedic spinal surgery between the experimental group and the control group

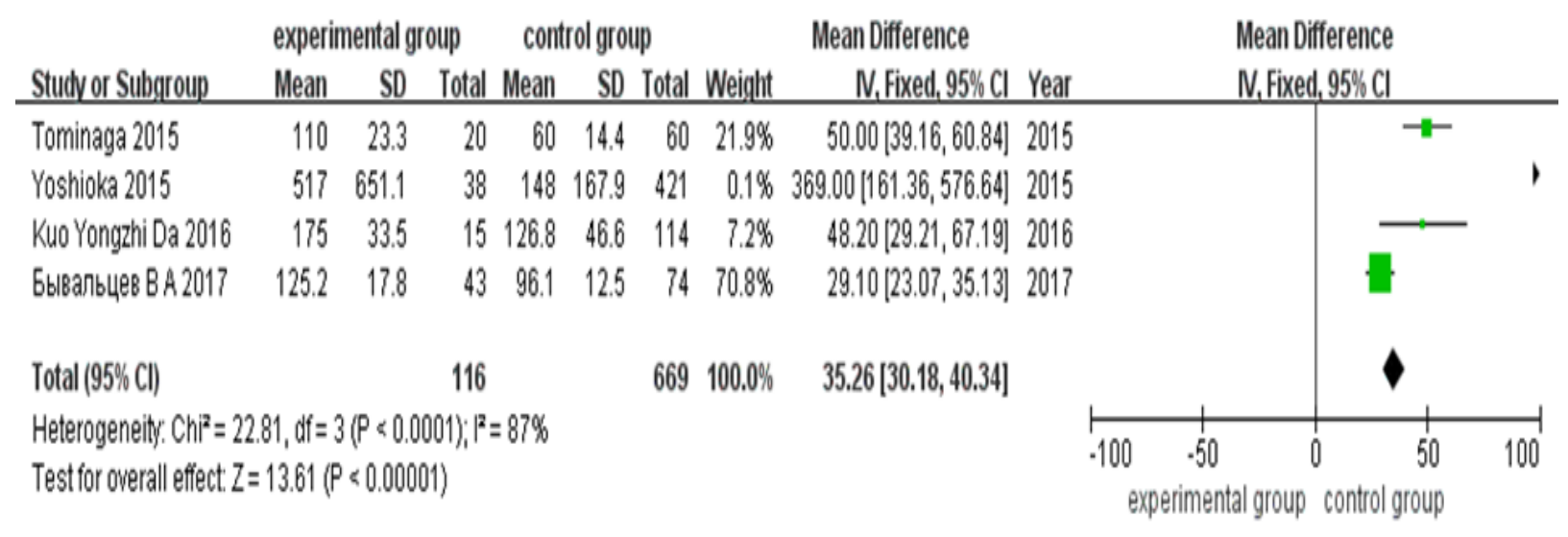

Fig. 6: Meta-analysis of blood loss comparison of venous thrombosis patients

Meta-analysis of blood loss comparison of venous thrombosis patients in the perioperative period of orthopedic spinal surgery between the experimental group and the control group 
www.ijpsonline.com

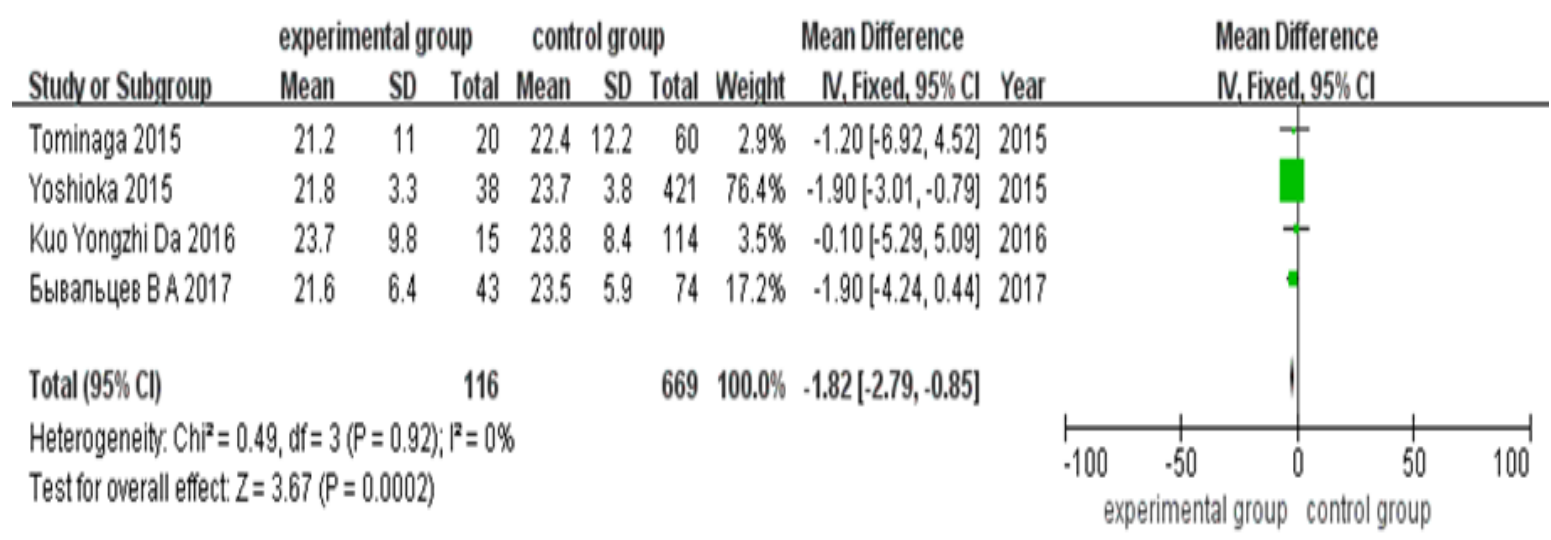

Fig. 7: Meta-analysis of BMI comparison of venous thrombosis patients Meta-analysis of the BMI comparison of venous thrombosis patients in the perioperative period of orthopedic spinal surgery between the experimental group and the control group

is contrary to the conclusions of the previous studies ${ }^{[18]}$. It is believed that the reasons for the inconsistent conclusions could be related to the small number of samples selected in this paper and the untimely return visit after operation. In addition, the results of the meta analysis showed that the operation time of the experimental group was significantly higher than that of the control group, indicating that the surgery time was one of the main factors of thrombosis in the perioperative period of orthopedic spinal surgery and long operation times might lead to a high incidence of thrombosis in orthopedic spinal surgery. However, the risk of thrombosis can be decreased by initiating factor Xa inhibitors immediately after the surgery thus preventing venous thromboembolism. Although this paper puts forth these conclusion which is basically consistent with the previous research, it still has some limitations. First of all, more comprehensive research literatures were obtained by the literature retrieval in a large number of databases, and the final literatures were obtained through the literature screening by the professionals. However, there was still a certain selective bias. Secondly, there were many results of meta-analysis on the perioperative risk factors of orthopedic spinal surgery, but due to the different research methods and evaluation methods in different research teams, the risk factors of thrombosis were quite different, resulting in the biased conclusions. Finally, through the investigation, it was found that although there were many literatures related to the orthopedic spinal surgery, there were relatively few literatures about the risk factors of thrombosis in the perioperative period of orthopedic spinal surgery, especially high-quality papers. And there were few references used in this paper, which limits the authenticity of the research, and affect the analytical conclusions. Therefore, the author believes that a joint study and the cooperation of multiple teams should be adopted to comprehensively evaluate the risk factors of thrombosis in the perioperative period of orthopedic spinal surgery. Finally, obtain the real risk factors of thrombosis in the perioperative period of orthopedic spinal surgery more effectively. To sum up, the risk factors of thrombosis in the perioperative period of orthopedic spinal surgery such as age, operation time, blood loss, gender and BMI have little effect on thrombosis. Despite the BMI has negligible effect to cause the thrombosis it is believed that obesity and less physical activity could be inter-related and the sedentary life style of obese patients could cause thrombosis. The age, blood loss, and BMI, operation time were positively correlated with thrombosis in the perioperative period of orthopedic spinal surgery.

\section{Author's contributions:}

Yang $\mathrm{Wu}$ conceived and designed the experiments. Xiongzhong $\mathrm{Li}$ and Jun Xuan performed the experiments. Hao Cheng analyzed the data and wrote the paper.

\section{Acknowledgements:}

This work was supported by Jinhua Municipal Central Hospital.

\section{Conflict of interests:}

The authors declared no conflict of interest.

\section{REFERENCES}

1. Saleh J, El-Othmani MM, Saleh KJ. Deep Vein Thrombosis and Pulmonary Embolism Considerations in Orthopedic Surgery. Orthop Clin North Am 2017;48:127-35.

2. Golubev GS, Sasko SS, Bachurin SS, Berezovskiy DP. 
Stratification of deep vein thrombosis and pulmonary embolism risk factors after trauma and orthopedic surgery. Medical Herald of the South of Russia 2018;9:17-28.

3. Takeuchi K. Perioperative Patients. Efficacy of Direct Oral Anticoagulants for the Treatment of Deep Vein Thrombosis in Orthopedic ESE College of Angiology. Journal JPN 2018.

4. Dapeng W, Fuqin B, Qiang L, Teng Y, Li J. Semiautomatic intermittent pneumatic compression device applied to deep vein thrombosis in major orthopedic surgery. Biomed Eng Online 2018;17:78.

5. Li Y, Wang ZY, Sang X. Subclavian vein thrombosis and fatal pulmonary embolism after proximal humerus fracture surgery. J Orthop Surg 2019; 27:2309499019832728.

6. Xu J, Ruofan Ma, Deng Li, Zhang Y, Cai Z, Huang Y, et al. The perioperative risk of deep vein thrombosis and individualized anti-coagulation treatment in patients with hepatic cirrhosis undergoing total hip arthroplasty: a pilot study. WPRIM 2015;35:1096-1104.

7. Schuster JM, Rechtine G, Norvell DC, Dettori, JR. The Influence of perioperative risk factors and therapeutic interventions on infection rates after spine surgery. Spine 2010;35:125-37.

8. Yamasaki K, Hoshino M, Omori K, Igarashi H, Tsuruta T, Miyakata $\mathrm{H}$, et al. Prevalence and risk factors of deep vein thrombosis in patients undergoing lumbar spine surgery. J Orthop Sci 2017.

9. Yi WL, Bin L. Advances in risk factors and prevention of deep venous thrombosis after spine surgery. Med Recapitulate 2016.

10. Yang SD, Liu H, Sun YP, Yang DL, Shen y, Feng SQ, et al. Prevalence and risk factors of deep vein thrombosis in patients after spine surgery: A retrospective case-cohort study. Sci Rep 2015;5:11834.

11. Samdani A, Belin E, Bennett J, Miyanji F, Pahys J, shah S, et al. Major perioperative complications after spine surgery in patients with cerebral palsy: assessment of risk factors. Euro Spine J 2016;25:795-800.

12. Wang C, Weng H, Li B, Ren X, Zeng X. Application of RevMan 5.3 software for data transformation in etiological and prognostic meta-analysis. Chinese J Evid Based Med 2017; 17:852-6.
13. Yoshioka K, Murakami H, Demura S, Kato S, Hiroyuki T. Prevalence and Risk Factors for Development of Venous Thromboembolism After Degenerative Spinal Surgery. Spine 2015;40:301-6.

14. Tominaga H, Setoguchi T, Tanabe F, Kawamura I, Tsuneyoshi Y, Kawabata N, et al. Risk Factors for Venous Thromboembolism After Spine Surgery. Medicine 2015;94:e466.

15. Rojas-Tomba F, Gormaz-Talavera I, Menendez-Quintanilla IE, Moriel-Duran J, García Quevedo-Puerta D, Villanueva-Pareja F. Incidence and risk factors of venous thromboembolism in major spinal surgery with no chemical or mechanical prophylaxis. Span J Orthop Surg Traumatol 2016;60:133-140.

16. Brad EZ, Sweena K, Evan DB, Gustav YC, William PC, Lily $\mathrm{M}$, et al. Incidence and risk factors for preoperative deep venous thrombosis in 314 consecutive patients undergoing surgery for spinal metastasis. J Neurosurg Spine 2017;27:18997.

17. Byvaltsev VA, Kalinin AA, Pestryakov AY, Shepelev VV, Stepanov IA. Analysis of Results of the Intervertebral Total Disk Arthroplasty of the Lumbar Spine by M6-L Prosthesis: A Multicenter Study. Annals of the Russian academy of medical sciences 2017;72:393-402.

18. Park JH, Lee KE, Yu YM, HwangPark Y, AnChoi S. Incidence and Risk Factors for Venous Thromboembolism After Spine Surgery in Korean Patients. World Neurosurg 2019;128:289307.

19. Frank JS, Nicola H, Virginie CL, Robert AH, Gregory M, Douglas CB, et al. Risk Factors for Major Perioperative Complications in Adult Spinal Deformity Surgery: A Multicenter Review of 953 Consecutive Patients. Spine 2010:70-1.

This is an open access article distributed under the terms of the Creative Commons Attribution-NonCommercial-ShareAlike 3.0 License, which allows others to remix, tweak, and build upon the work non-commercially, as long as the author is credited and the new creations are licensed under the identical terms

This article was originally published in a special
issue, "Biomedical Research in Healthcare Setting"
Indian J Pharm Sci 2020:82(3)Spl issue5;144-149

